\title{
Effects of morphology in controlling propagation of density currents in a reservoir using uncalibrated three-dimensional hydrodynamic modeling
}

\author{
Behnam Zamani, ${ }^{*}$ Manfred Koch, ${ }^{1}$ Ben R. Hodges ${ }^{2}$ \\ ${ }^{1}$ Department of Geohydraulics and Engineering Hydrology, Faculty of Civil and Environmental Engineering, University of Kassel, \\ Germany; ${ }^{2}$ Department of Civil, Architectural, and Environmental Engineering, University of Texas at Austin, TX, USA
}

\begin{abstract}
In this study, effects of basin morphology are shown to affect density current hydrodynamics of a large reservoir using a threedimensional (3D) hydrodynamic model that is validated (but not calibrated) with in situ observational data. The AEM3D hydrodynamic model was applied for 5-month simulations during winter and spring flooding for the Maroon reservoir in southwest Iran, where available observations indicated that large-scale density currents had previously occurred. The model results were validated with near-bottom water temperature measurements that were previously collected at five locations in the reservoir. The Maroon reservoir consists of upper and lower basins that are connected by a deep and narrow canyon. Analyses of simulations show that the canyon strongly affects density current propagation and the resulting differing limnological characteristics of the two basins. The evolution of the Wedderburn Number, Lake Number, and Schmidt stability number are shown to be different in the two basins, and the difference is attributable to the morphological separation by the canyon. Investigation of the background potential energy (BPE) changes along the length of the canyon indicated that a density front passes through the upper section of the canyon but is smoothed into simple filling of the lower basin. The separable dynamics of the basins has implications for the complexity of models needed for representing both water quality and sedimentation.
\end{abstract}

\section{INTRODUCTION}

Reservoirs, as artificial lakes, have characteristics and behaviors that differentiate them from most natural lakes due to rift-like depths and downstream flow controls (Ford and Johnson 1986). The assessment and prediction of physical and bio-geochemical processes (hereafter biochemical for simplicity) and their causes within reservoirs are important for both operations and environmental issues. Physical processes are drivers and controls of biochemical processes and play a key role in ecosystem behaviors. Among the former, the most important ones are hydrodynamic processes which dictate

Corresponding author: behnam.zamani@uni-kassel.de

Key words: Hydrodynamic modeling; AEM3D, three-dimensional model; reservoir morphology; background potential energy; stratification; mixing.

Edited by: Marco Toffolon, Department of Civil, Environmental and Mechanical Engineering, University of Trento, Italy.

Received: 9 September 2019

Accepted: 17 April 2020.

This work is licensed under a Creative Commons Attribution NonCommercial 4.0 License (CC BY-NC 4.0).

${ }^{\circ}$ Copyright: the Author(s), 2020

Licensee PAGEPress, Italy

J. Limnol., 2020; 79(3): 238-253

DOI: 10.4081/jlimnol.2020.1942 the stratification and mixing that control the temporal and spatial distribution of nutrients and dissolved oxygen (Vincent et al., 1991; Hamilton and Schladow, 1997; Schladow and Hamilton, 1997; Löffler, 2004).

Although hydrodynamics and water quality for natural lakes is a well-studied subject, and much of the research carried out up to date is applicable for issues common to both lakes and reservoirs (Jørgensen et al., 2005), specific differences between the characteristics of natural lakes and reservoirs (e.g. being embedded in river networks where natural geology would not allow impoundment, the location of deepest portions, water release locations) leave a range of issues where the natural lake literature does not provide much guidance (USACE, 1987; Hayes et al., 2017). One primary difference is that reservoirs are geologically "young," which leads to geological complexities that would be smoothed by centuries or millennia of sedimentation and erosion in a natural lake. As a result, reservoirs have morphologic complexities that often lead to deeper depths, steeper slopes, and long water residence times.

Numerous morphometric parameters, e.g. bathymetry, volume, area and depth, are controlling limnological and hydrodynamic characteristics of a reservoir and directly affect hydrodynamic processes, oxygen exchange, nutrient cycles and other water quality-related biochemical processes. The morphometric parameters are mutually connected, and their assessment provides insight into the present and likely future status of a reservoir. Reservoirs are typically located to maximize water storage for a minimum dam area, which typically results in deeper depths, stronger stratification, and different limnological indices than those of natural lakes in the 
same region (Kennedy et al.,1985; Thornton et al., 1996). From a hydrological perspective, many reservoirs are the water sink for a larger watershed than a natural lake of similar size (Ji, 2008), which can result in higher nutrient and sediment inflows and strong seasonal variation. As a further complexity, reservoirs typically have controlled in-/outflows at various depths varying from surface to bottom (Ji, 2008), which can affect the stratification regime (Imberger and Patterson, 1990).

When a storm flood enters a stratified reservoir, unless its water has precisely the same density as the reservoir water, it forms a density current as an underflow, interflow, or overflow (Ford and Johnson, 1983). Density current behaviors, such as travel time throughout the reservoir, thickness of the current, dilution rates, current temperature, suspended sediment concentration and the consequent turbidity are affected by reservoir stratification and also have feedbacks that alter the stratification (Chung et al., 2009; Cortés et al., 2014). Unfortunately, the interplay between density currents, stratification, and internal processes of a reservoir cannot be quantified with simple analytical expressions and, thus, computational approaches are required. Numerical modeling of density-current hydrodynamics provides insight into how these currents interact with the stratification and mixing processes. Such insight can assist in developing reservoir operating procedures to reduce undesirable effects of inflows (e.g., increase in stratification and longer residence time in the hypolimnion).

Hydrodynamic models are used to simulate the behavior of lakes and reservoirs under various forcing conditions. Different physical and biochemical aspects of reservoirs have been investigated and numerically modeled in several studies. Hodges et al. (2000) and Hodges et al. (2006) studied basin-scale internal waves and their uncertainties in stratified lakes and demonstrated the good ability of the 3D-hydrodynamic model in predicting the internal waves dynamics and mixed layer depth, even for coarse vertical resolutions. Botelho and Imberger (2007) and Hipsey et al. (2008) modeled pollutants fate and transport in reservoirs and lakes. Zamani et al. (2018) modeled the hydrological effects on the limnological processes in reservoirs. A considerable number of studies, e.g. Bournet et al. (1999), Chung et al. (2009), Marti et al. (2011), An et al. (2014), Cortes et al. (2014), Hogg et al. (2017) have investigated and modeled the propagation density currents in various stratified reservoirs, either at laboratory or geophysical scale.

However, the interplay between the dynamics of density currents and reservoir morphometry appears to have received not enough attention in the previous studies. Even in studies involving the lakes' morphometry, e.g., multi-basin or dendritic lakes and reservoirs, the focus has been mostly on the analysis of the performance of the numerical model (e.g. Rueda and McIntyre, 2010) or the prediction of the distribution of the density currents or their resulting sedimentation (e.g. Kim and Kim, 2006; Scheu et al. 2018).

In this study we investigate and model how the morphology of a reservoir affects its hydrodynamics and propagation of density currents. The study object is the Maroon reservoir in southwest Iran. The Maroon reservoir consists of upper and lower basins that are connected through a narrow and deep canyon. We examine the different hydrodynamic behaviors in the basins under extreme events that are affected by the narrow canyon during a 5-month flooding period in 2011-12. During that time measurements of water temperature in the reservoir were taken by the local water authority, mainly in the upper basin, however, with only limited measurements in the lower basin. Although this limited data is insufficient for evaluating the physics of storm-driven density currents, such information is needed for reservoir managers to evaluate operational strategies. Notwithstanding these shortcomings, in this paper we show that this limited data is sufficient to validate an uncalibrated three-dimensional (3D) hydrodynamic model, allowing to get deeper insight in the physical processes taking place in the Maroon reservoir.

\section{METHODS}

\section{Study area}

The Maroon reservoir is located on the Maroon River in southwest Iran (Fig. 1). The Maroon dam is located 13 $\mathrm{km}$ northeast of Behbahan city. The reservoir provides storage of irrigation water, hydropower, and serves as flood control for the Maroon River, one of the large rivers in Iran with a long-term annual mean flow upstream of the Maroon reservoir of $47 \mathrm{~m}^{3} \mathrm{~s}^{-1}$, although the flow in any year is seasonally variable. The maxima and minima of the monthly flow happen typically in April (snowmelt) and October, respectively, and the flooding season typically starts in December.

The Maroon reservoir and dam began operation in 2000 , so the reservoir is a young lake from a limnological point of view (Ford and Johnson, 1986). The reservoir has a catchment area of $3840 \mathrm{~km}^{2}$ in the Zagros Mountains. The mean depth of the Maroon reservoir (the ratio of full storage volume to surface area) is $49 \mathrm{~m}$, which classifies it as a deep reservoir $(\mathrm{Ji}, 2008)$. The reservoir is formed in a valley with steep side slopes, especially in the upper reservoir, and can be conceptually divided into an upper and lower basin separated by a narrow and deep canyon (Fig. 1c). Of the $30 \mathrm{~km}$ of the reservoir's thalweg approximately $17 \mathrm{~km}$ extends over the upper basin. The major part of the upper basin is formed in the narrow and 
long valley of the Maroon River, with a width ranging between 100 and $650 \mathrm{~m}$ (at the Normal Pool Level NPL). The canyon connecting the two basins is $2400 \mathrm{~m}$ long, with a width ranging between $170 \mathrm{~m}$ and $350 \mathrm{~m}$ at NPL. Based on volume, thalweg length, and flows, the reservoir has a mean water residence time of 1.27 years.

The Maroon reservoir is classified as a warmmonomictic lake using the thermal classification of lakes suggested by Hutchinson and Löffler (1956). This implies a major stratification in summer and a major overturn and mixing period in winter. Most of the Iranian lakes and reservoirs, especially in our study region (Khuzestan province and Zagros region), are also in this category. The winter mixing period in the lakes and reservoirs of the study area is in December. In this time of the year the onset of the flooding period of the Maroon River occurs also, providing cold flood inflows into the reservoir due to cold winter precipitation. Simultaneously, air temperature and the solar radiation start to increase after January, so the stratification gradually develops in the reservoir water column.

\section{Data}

The nearest meteorological station is the Behbahan synoptic station, $13 \mathrm{~km}$ southwest of the Maroon dam, which provides meteorological data for this study. The data are available from 1994 as hourly records of air temperature, atmospheric pressure, wind, cloudiness and humidity, and are used to set the thermal and wind stress boundary conditions of the model. The solar (shortwave) radiation is not measured directly at the Behbahan station and, therefore, was estimated from the measured bright sunshine data using the FAO procedure (Allen et al., 1998) for the station by implementing the Angström coefficients (Ångström, 1924), calculated and validated for the region by Hajjam and Jamei (2009). Yang and Koike (2005) found underestimations of up to $10 \%$ in the calculated peaks of hourly solar radiation using this method in mountainous areas (in Japan). However, studies on the solar radiation in Iran (Alizadeh and Khalili, 2009, Hajjam and Jamei, 2009) found no significant difference between FAO - calculated and observed solar radiation values in Iran, including the present study area (Khuzestan province).

The river flow at the Eydanak station is available throughout the year as daily mean flows, with more frequent (hourly) measurements during the flooding seasons.

Continuously-measured water temperatures were available for the Maroon reservoir at the upstream inflow of the Maroon River and at five locations across the reservoir (Fig. 1c) for a limited time interval. These data were measured using RBR logging sensors moored at stations R, St1, St2, St3, St4 and St5 (Fig. 1c) in the hypolimnion at $2 \mathrm{~m}$ above the bottom. The sensors were deployed in the flooding season between December 2011 and April 2012 (Mehrabani et al., 2013). The recorded water temperatures at station $\mathrm{R}$ were used for the inflow boundary conditions and those from St1 through $\mathrm{St} 5$ for comparisons with the model's results.

\section{Model description and setup}

\section{Model description}

The Aquatic Ecosystem Model AEM3D (Hodges and Dallimore, 2016) is a three-dimensional hydrodynamic and ecosystem model for estuaries, lakes and reservoirs, and allows to predict water temperature, salinity, nutrients and biota variations in space and time. AEM3D uses the unsteady Reynolds-Averaged Navier-Stokes (RANS) and scalar transport equations with the Boussinesq and hydrostatic approximations. This model is an improved version of the ELCOM (Hodges, 2000) hydrodynamic and CAEDYM (Hipsey et al., 2006) ecosystem models. Here we only use the hydrodynamic module of the model, as the focus is only on an analysis of the physical processes of the Maroon reservoir.

In AEM3D, the typical $k-\varepsilon$ or eddy viscosity turbulence models (e.g., see Zamani and Koch, 2020) are substituted with a standalone $3 \mathrm{D}$ vertical mixing model (Hodges et al., 2000) to predict the wind-mixed layer depth and a model to more precisely model the distribution of momentum over the depth. The latter, being separately applied in the $\mathrm{x}$ and $\mathrm{y}$ directions, provides a direct increase in the velocity field of the windmixed layer before the Navier-Stokes equations are solved. A detailed description of the equations solved in AEM3D and further explanations of the underlying theory are provided in Hodges (2000) and Hodges et al. (2006).

AEM3D uses a modified adaptation of the TRIM-3D approach of Casulli and Cheng (1992) as its numerical scheme. The solution grid is a rectangular Cartesian grid with fixed longitudinal and lateral grid dimensions horizontally ( $\Delta x$ and $\Delta y$ ) and a vertical $\Delta z$ spacing which is horizontally uniform but can vary in vertical dimension (e.g. different vertical layer thicknesses). The grid stencil is based on Arakawa's C-grid (Arakawa and Lamb, 1977) in which velocity vector values are defined on cell faces and scalar values (e.g. concentrations) on cell centers. The TRIM-3D approach is a semi-implicit finite difference method that numerically solves the $3 \mathrm{D}$ shallow-water equations for stratified flows.

\section{Model setup and parameters}

The AEM3D model allows the inclusion of Coriolis rotational effects, which are important for some large lakes/reservoirs. However, using this feature substantially increases the computational execution time and should 
only be used when warranted. Coriolis is generally considered significant when the Rossby radius of deformation $L_{R}$ (Wüest and Lorke, 2003) is less than the lateral length scale of the system. The $L_{R}$ is computed as the ratio of inertial- to Coriolis forces:

$$
L_{R}=\frac{C_{I}}{f}
$$

where is the phase speed of internal gravity waves given by $C_{I}=\left(g^{\prime} D\right)^{(1 / 2)}$, with $g^{\prime}$ the reduced gravity due to stratification, $D$ the water depth and $f$ the Coriolis parameter. Using eq. (1) with appropriate parameters $D$ and $f$ for the Maroon reservoir, the Rossby radius $L_{R}$ is calculated as $11000 \mathrm{~m}$, which is larger than the lateral dimensions (4000-5000m) of the main basins. Thus, the standard approach indicates that the Coriolis force can be safely neglected in modeling the Maroon reservoir. However, a recent study by Amadori et al. (2019) argued that the Rossby radius criterion is only valid for investigating the Coriolis effect for inertial currents and barotropic and baroclinic waves, whereas the Ekman number could be a more important criterion for evaluating the Coriolis effect for wind-induced steady circulation. To date, tests of their hypothesis are limited to steady-state simulations in a one-dimensional and rectangular (with flat bottom) domain, and thus it is not clear whether it should apply to complex morphometry in a 3D basin with unsteady wind and flow conditions. To evaluate the relevance of the arguments of Amadori et al. (2019) to the present work, we performed a matched set of one-monthlong simulations of the Maroon Reservoir with Coriolis both on and off. The differences between these two simulations had a root-mean-square error (RMSE) of $0.12^{\circ} \mathrm{C}$. Furthermore, there were no significant differences in mean values $(\mathrm{P}=0.004)$. Thus, we argue that Coriolis forcing can be neglected for the Maroon reservoir's hydrodynamics and the Ekman number hypothesis of Amadori et al. (2019) requires further evidence for its extension to complex morphometry and unsteady forcing.

For the model grid of the Maroon reservoir a horizontal cell size of $\Delta x=\Delta y=100 \mathrm{~m}$, as shown in Fig. $1 \mathrm{c}$, was used. In the vertical, layers have a uniform

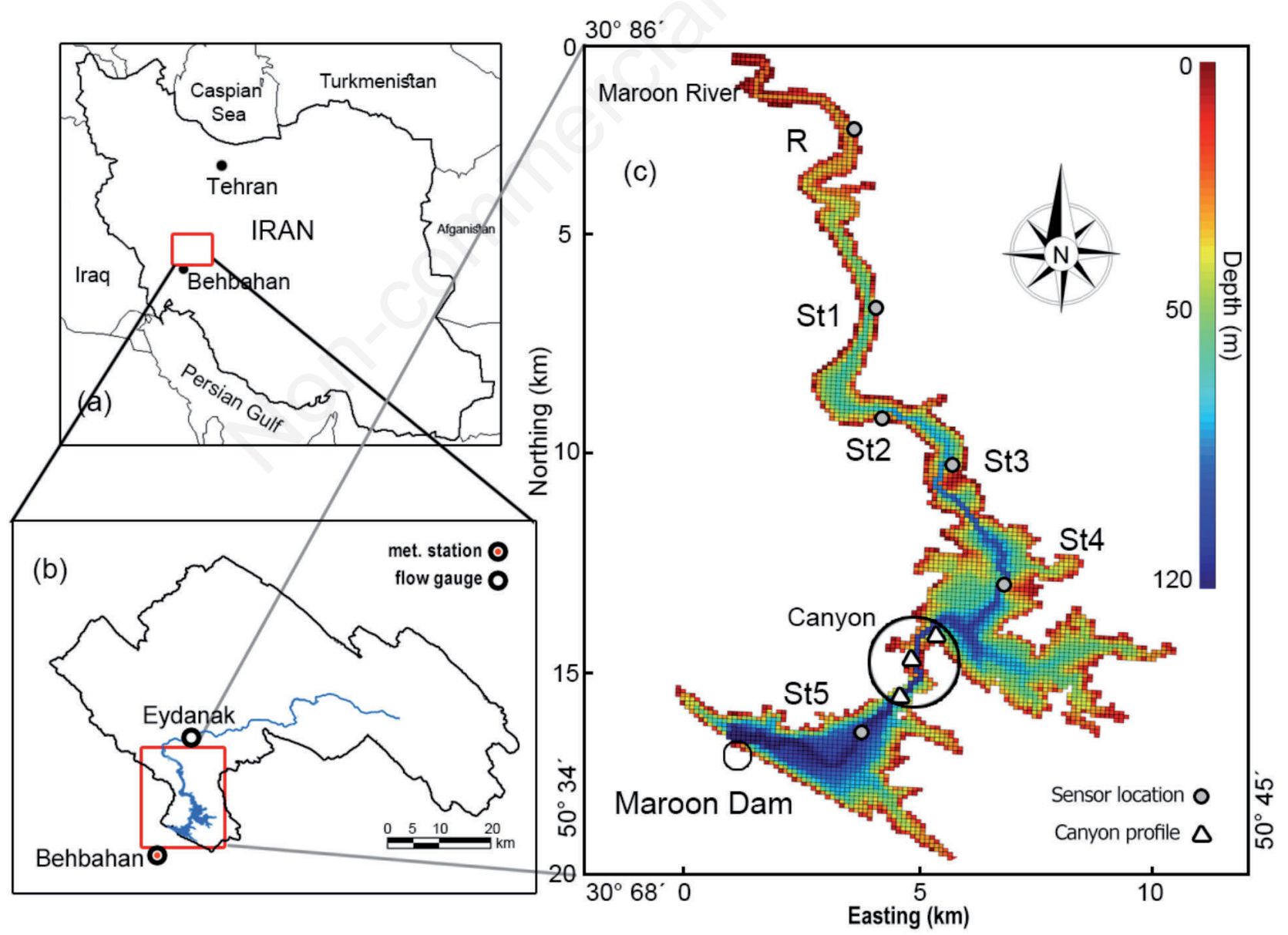

Fig. 1. a) Location of the Maroon reservoir. b) Maroon reservoir catchment and the location of the Behbahan meteorological station. c) AEM3D model grid with bathymetry of the Maroon reservoir with the canyon and sensor locations. 
vertical separation of $\Delta \mathrm{z}=1 \mathrm{~m}$. The $100 \mathrm{~m}$ horizontal cell size is a compromise that allows reduced computational time while still capturing the complex bathymetry of the Maroon reservoir and the deep canyons. Based on these cell dimensions the domain has a total of 185,314 valid wet cells, with 4803 horizontal cells across the free surface at maximum pool level. A model time step of 40 seconds is used, as it satisfies the model's CFL stability criteria (Courant-FriedrichsLewy condition) for all model runs. The model was run on a Linux cluster supercomputer of the University of Kassel with AMD $2.6 \mathrm{GHz}$ processors $(2 \times 16$ cores, 32 threads) using the OpenMP parallel computing approach.

The AEM3D model requires a number of physical parameters, which may be either a priori fixed to literature values or calibrated based on site-specific data. Parameters such as light extinction coefficient, wind drag coefficient, and bottom drag coefficient will affect the evolution of physical processes (e.g., stratification, mixing, internal waves and motion of density currents) within a lake and may differ from one lake to another. Ideally, such parameters should be calibrated with a sitespecific study; however, where in situ data are scarce or non-existent, prior research has shown that the hydrodynamics of a reservoir can be reasonably represented in a 3D model using standard coefficients from the literature. The AEM3D model has previously been shown to represent complex hydrodynamic processes - e.g. internal waves (Hodges et al. 2006), propagation of density currents (Chung et al. 2009) and provide good agreement with field measurements for surface thermodynamics and mixing processes using literature parameters (Chung et al., 2009; Marti et al., 2016; Zamani et al., 2018) even in the Maroon reservoir (Zamani and Koch, 2020). Models using literature values are typically termed "uncalibrated," although the literature parameter values are generally based on observations and analyses over multiple sites and thus represent a form of generic calibration. Due to scarcity of observational data, site-specific calibration was not possible for the present study. The literature parameter values used herein are shown in Tab. 1.
Further details of the AEM3D model set up, including specifics of the implementation of the boundary conditions for the Maroon reservoir are provided in Zamani and Koch (2020).

\section{Model statistical evaluation}

The model performance and accuracy are evaluated using the absolute mean error (AME) and the root mean square error (RMSE) applied to modeled and measured water temperature:

$$
\begin{aligned}
& A M E=\frac{1}{n}\left(\sum_{i=1}^{n}\left|Y_{i}^{o b s}-Y_{i}^{\text {mod }}\right|\right) \\
& R M S E=\sqrt{\frac{1}{n} \sum_{i=1}^{n}\left(Y_{i}^{o b s}-Y_{i}^{\text {mod }}\right)^{2}}
\end{aligned}
$$

where $Y_{i}^{\text {obs }}$ is the observed value measured at the station, $Y_{i}^{\text {mod }}$ is the corresponding value simulated by the model, and $n$ is the number of data values.

\section{Density currents and limnological analysis}

To analyze flood propagation through the Maroon reservoir, the AEM3D simulation was started in the middle of December 2011 when the reservoir, after the winter overturn, had a slight vertical temperature gradient $\left(17^{\circ} \mathrm{C}\right.$ at the surface and $16^{\circ} \mathrm{C}$ at the bottom). Our analyses herein focus on the propagation of the cold density currents from the flood events of January 14 and February 2, as the ensuing density signals were clearly visible in both the modeled and measured data. The current speed and the effects of the currents on the water temperature balance within the reservoir at the up- and downstream basins are also investigated below.

The Wedderburn Number $(W)$, Lake Number $\left(L_{N}\right)$ and the Schmidt stability $\left(S_{t}\right)$ are typically used with long-term data sets to analyze the limnological and hydrodynamic status of lakes. These indices provide general information on the mixing processes in the lake due to wind forcing $(W)$ and the stratification/stability of the lake $\left(L_{N} / S_{t}\right)$.

\begin{tabular}{|c|c|c|c|}
\hline Parameter & Description & Unit & Value \\
\hline$C_{D}$ & Bottom drag coefficient & - & 0.05 \\
\hline$\lambda_{P A R}$ & Light extinction coefficient for Photosynthetically Active Radiation & $\mathrm{m}^{-1}$ & 0.25 \\
\hline$\alpha_{s w}$ & Mean albedo for short-wave radiation & - & 0.08 \\
\hline$\alpha_{l w}$ & Mean albedo for long-wave radiation & - & 0.03 \\
\hline$C_{d}$ & Wind stress coefficient & - & 0.0013 \\
\hline
\end{tabular}

Tab. 1. Parameters used in the AEM3D. 
The Wedderburn Number (Imberger and Patterson, 1990) is defined as:

$$
W=\frac{g^{\prime} h_{1}^{2}}{u_{*}^{2} L}
$$

where $g^{\prime}$ is the reduced gravity, i.e. $g^{\prime}=g \Delta \rho \rho^{-1}$ where $\Delta \rho$ is the density difference across the thermocline, $h_{1}$ is the upper layer thickness, $L$ is the fetch length, and $u_{*}{ }^{2}$ is the wind stress which is computed from the wind speed as follows:

$$
u_{*}^{2}=C_{d}\left(\frac{\rho_{a}}{\rho_{w}}\right) W^{2}
$$

where $C_{d}$ is the wind stress coefficient (Tab. 1), $\rho_{a}$ is the air density, $\rho_{w}$ is the water density and $W$ is the wind speed.

The Lake Number is calculated as (Imberger and Patterson, 1990; Robertson et al., 1994):

$$
L_{N}=\frac{S_{t}\left(1-\frac{z_{T}}{Z}\right)}{\rho_{0} u_{*}^{2} A_{m}{ }^{3 / 2}\left(1-\frac{z_{g}}{Z}\right)}
$$

where $z_{g}$ is the location of the lake's center of volume, $z_{T}$ is the height to the center of the metalimnion (thermocline height), $z_{0}$ is the center of gravity of the water mass with a density stratification $r(z)$ at height $z$ above the lake bottom, $M$ is the total mass of the water, $A_{m}$ is the surface area of the lake at the maximum height and $g$ is the acceleration of gravity $\left(\mathrm{m} \mathrm{s}^{-2}\right)$.

The Schmidt stability term $S_{t}\left(\mathrm{~J} \mathrm{~m}^{-2}\right)$ (Schmidt, 1928; Hutchinson, 1957) that defines the work needed for mechanically mixing the entire water body into a uniform density distribution without any heat exchange is calculated as follows:

$$
S_{t}=\frac{g}{A_{M}} \int_{0}^{z_{m}}\left(z-z_{g}\right) A_{z}\left(1-\rho_{z}\right) d z
$$

where $z$ is the height above bottom (cm), $A_{M}$ is the lake surface area $\left(\mathrm{cm}^{2}\right)$ at the maximum height, $A_{z}$ is the lake surface area $\left(\mathrm{cm}^{2}\right)$ at the height of $z$, and $\rho_{z}$ is the water density $\left(\mathrm{g} \mathrm{cm}^{-3}\right)$ at height of $z$. The three quantities mentioned above were calculated from the model results for the Maroon reservoir using the Lake Analyzer MATLAB toolbox (Read et al., 2011).

\section{RESULTS}

\section{Model validation and robustness analysis}

Statistical results of the model validation for the water temperature are shown in Tab. 2. Overall, a good consistency between simulated (using the parameters' literature values of Tab. 1 without site-specific calibration) and observed temperatures is noticed. The AME and RMSE at the five stations are below $1^{\circ} \mathrm{C}$, with the exception of the RMSE at St4, which is only slightly above $1{ }^{\circ} \mathrm{C}$. The overall temperature range is $11-16^{\circ} \mathrm{C}$ (Fig. 2) so we argue the model-observations are in reasonable agreement relative to this range. Note that this level of error is lower than that of some previouslypublished studies (Chung et al., 2009; Lindim, 2010).

Continuous plots of the simulated and measured temperatures are shown in Fig. 2. Recall that the measured values at each station are taken at $2 \mathrm{~m}$ above the bottom and, hence, the large temperature falls observed in the various station plots of Fig. 2 are the consequence of the arrival of a cold-water density underflow in the wake of the two named flood events. To evaluate the modelledobserved data differences, note that the model values at a computational cell represent a volume of $\sim 10^{4} \mathrm{~m}^{3}$, whereas the measurements at a sensor point represent less than $1 \mathrm{~cm}^{3}$. This means that some differences are to be expected even for a perfect model. An overall good agreement between the temperature trends for all stations can be seen in Fig. 2. In contrast, we observe discrepancies for the large flood events, which increase from upstream station $\mathrm{St} 1$ to downstream station $\mathrm{St} 5$, and cannot simply be attributed to the difference between sensor volumes and model cell volumes.

\section{Flood propagation analysis}

Vertical profiles for the five months of simulated water column temperatures at the observation locations are shown in Fig. 3. The pathways of the two major flood events on January 14 and February 2 are shown in Fig. 4 and Fig. 5, respectively. A turbulent and relatively mixed

\begin{tabular}{|c|c|c|c|c|}
\hline Station & Mean (simulated) & Mean (observed) & AME & RMSE \\
\hline St1 & 14.96 & 14.27 & 0.82 & 0.97 \\
\hline St2 & 14.48 & 14.57 & 0.41 & 0.71 \\
\hline St3 & 14.97 & 14.59 & 0.65 & 0.81 \\
\hline St4 & 13.98 & 14.19 & 0.88 & 1.07 \\
\hline \multirow[t]{2}{*}{ St5 } & 13.08 & 13.05 & 0.71 & 0.91 \\
\hline & & mean & 0.70 & 0.89 \\
\hline
\end{tabular}
water column exists in the transition zone, characterized by stations St1 - St3 (Fig. 3 b-d), where the advective

Tab. 2. Statistical results of the AEM3D temperature validation $\left({ }^{\circ} \mathrm{C}\right)$. 
downslope propagation of the flood is the dominant factor in pushing the density current forward. The first flood event entering the reservoir was on January $14\left(\sim 150 \mathrm{~m}^{3}\right.$ $\mathrm{s}^{-1}$ ) and propagated as an underflow into the upper basin. This underflow took approximately 10 days to reach the downstream dam wall (Fig. 4), with an average propagation speed of $0.042 \mathrm{~m} \mathrm{~s}^{-1}$. The minimum temperature of the current front at the river inflow point was $11.6^{\circ} \mathrm{C}$ while the density current front temperature reaching the dam wall was $14.5^{\circ} \mathrm{C}$, showing the effect of initial mixing and entrainment of ambient waters during the transit. Initial mixing is the cumulative mixing happening in the vicinity of the plunge point where the river channel flow changes to a stratified flow. Entrainment of the ambient water into the current occurs by the turbulence generated from both interfacial shear and the bottom roughness affecting the density current
(Ford and Johnson, 1983; Hürzeler et al., 1996; Scheu et al., 2018). The reservoir was strongly affected by the second large flood on February 2, when the momentum of the inflowing density current (with a $9^{\circ} \mathrm{C}$ inflow temperature) dominated the buoyancy in the transition zone and mixed the entire water column during the peak of the flood event. After the density current passed through this zone, the water column remained nearly mixed for roughly three days (Fig. 5). Then the buoyancy forces dominated the weakened current during the recession limb of the flood hydrograph, pushing the mixed zone back, until the temperature stratification status came to an equilibrium within 10 days (Fig. 3 c,d). Further downstream, as the underflow transited into downstream (St4 to St5), buoyancy forces dominated and turbulence was suppressed by stratification. At station St4 the density current was seen to arrive as a bore that is rapidly

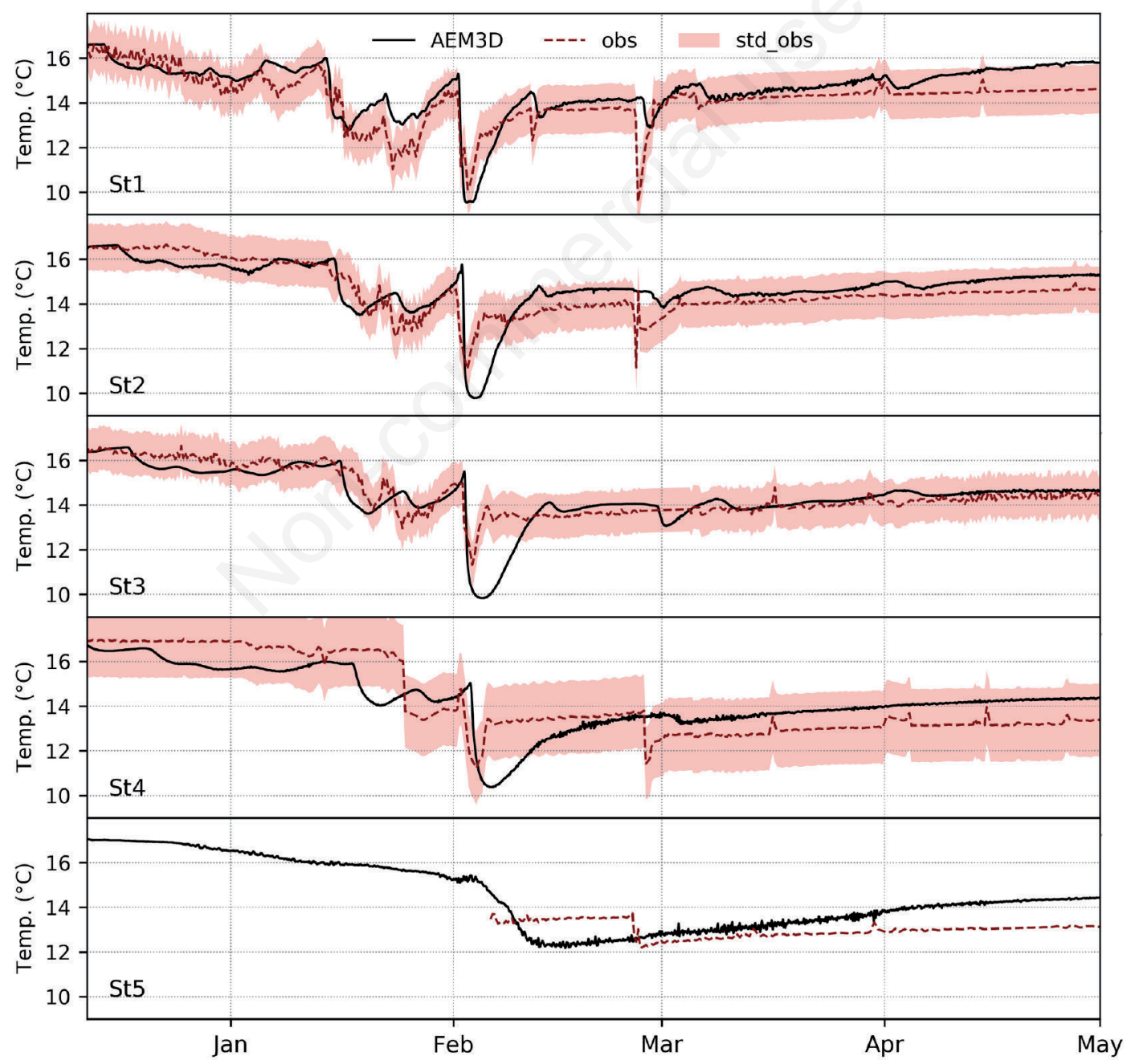

Fig. 2. Simulated (black line) water temperature at the measurement stations versus the measured values (red dashed line) at $2 \mathrm{~m}$ above bottom at each station. The light red bands denote the standard deviation of measured data. Note that the measured data for St5 are only available for February and later. 
dissipated in the deepest sections which manifests itself in the form of some oscillations of the $14^{\circ} \mathrm{C}$ temperature contour, indicating the existence of internal waves propagating through the system. On the other hand, at the most downstream station St5 in the lower basin the dense current fills the lacustrine zone completely and slowly
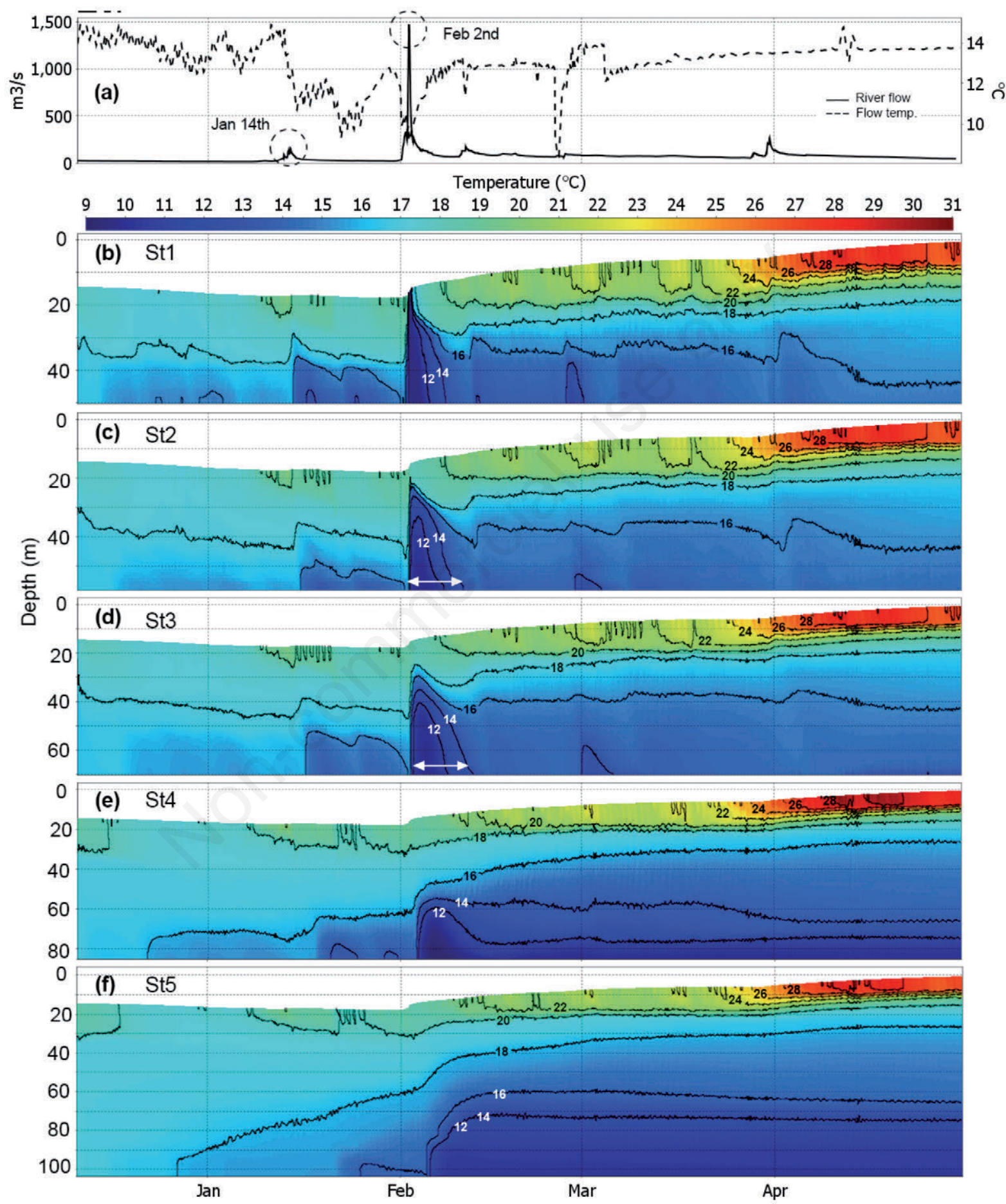

Fig. 3. a) Measured river inflow rate (continuous line) and temperature (dashed line) into the Maroon reservoir; temporal variation of the simulated water temperature by AEM3D as hourly profiles of water column temperature at (b), (c) and (d) transitional zone, (e) upper lacustrine zone and, (f) lower lacustrine zone. The white arrows show the 10 days period after the February $2^{\text {nd }}$ flood in the transition zone (see text for more information). 
over time (Fig. 3f), which indicates that the upstream bore has dissipated and substantial internal waves are not generated in this downstream section of the reservoir. These results prove that the sharp temporal changes associated with the flood are weakened through the canyon connecting the upper and lower basins.

\section{Effects of the narrow canyon}

\section{Limnological effects}

The narrow canyon (Fig. 1c) divides the reservoir into two basins. The upper basin, sampled by stations $\mathrm{St} 1, \mathrm{St} 2$,
St3 and St4, is strongly affected by the dynamics of the density underflow, whereas the lower basin, with station $\mathrm{St} 5$, is dominated by the spring warming. These effects can be better understood by examining the Wedderburn Number $(W)$ and the Lake Number $\left(L_{N}\right)$ which were shown by Imberger and Patterson (1990) to be separate indicators of mixing and stratification patterns, respectively: in a three-layered stratified system, in case of a small $W$ and a large $L_{N}$, only the upper region of the thermocline responds to wind forcing, while in case of both large $W$ and $L_{N}$ the entire water column in the lake is affected and responds to the wind forcing. The transitional

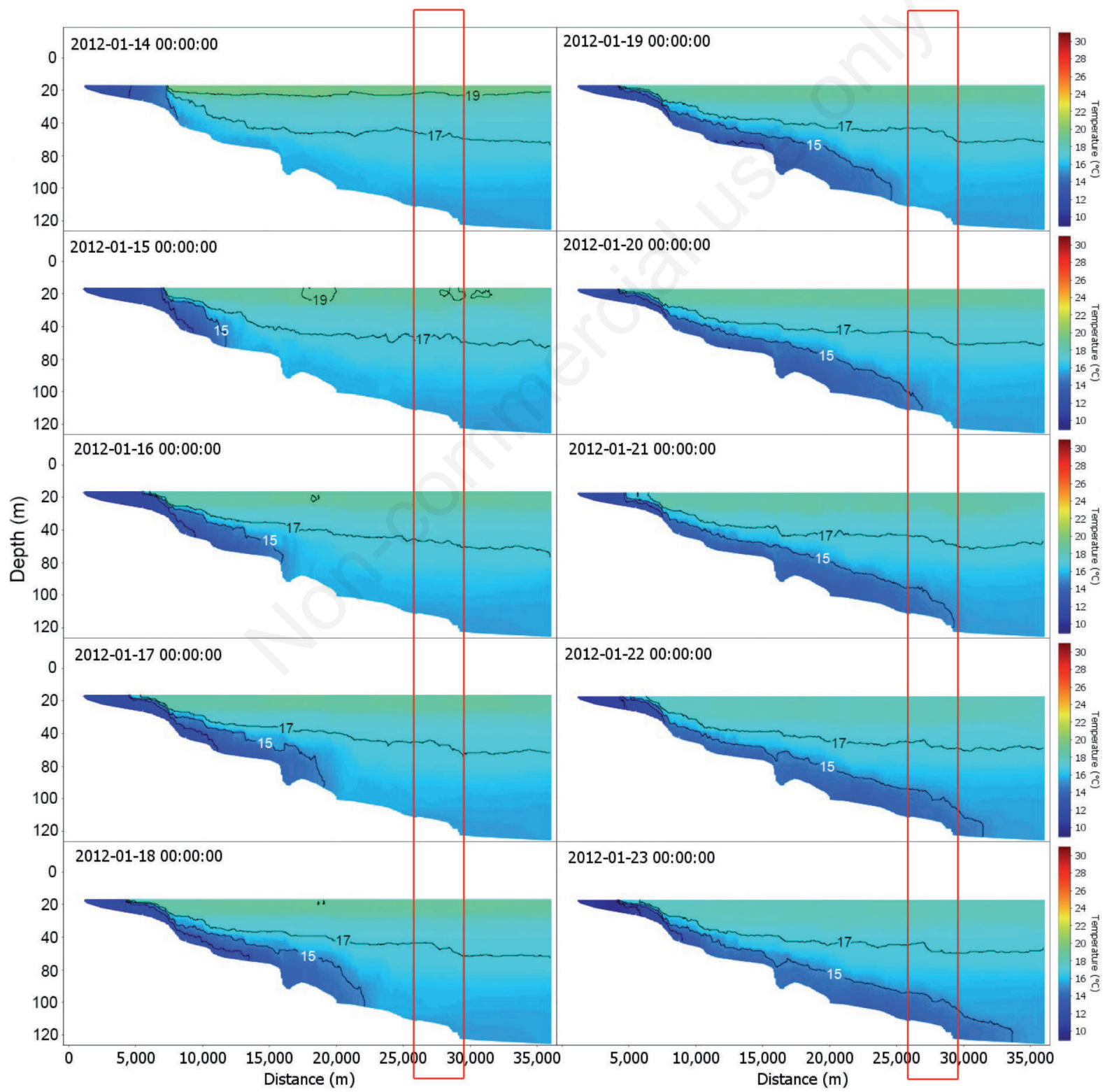

Fig. 4. Pathways of the flood event of January 14 and 10 days afterwards, through the reservoir's thalweg. The red boxes denote the canyon separating the two reservoir basins. 
evolution of these two numbers over the simulation horizon is shown for the two basins in Fig. 6, wherefore the upper basin has been represented by (the most appropriated) station St4 and the lower one by station $\mathrm{St} 5$.

The plots show that the variations of $W$ and $L_{N}$ in the upper and lower basin are evolving (with relatively large values) in parallel up to the beginning of March. These values diverge after that time, with $L_{N}$ strongly declining in the upper basin. In Fig. 6 a,b, time intervals of $L_{N}>>1$ and $W>>1$ are seen, especially in the upstream basin. Generally, the combination of $L_{N}>>1$ and $W>>1$ is considered to represent strong stratification (Imberger and
Patterson, 1990; Robertson and Imberger, 1994); however, the overall weak stratification seen in January and February (see also Fig. 7, to be discussed in the subsequent section) coincident with $L_{N}>>1$ and $W>>1$ implies that these large values mainly reflect the density current propagation and turbulent entrainment of overlying waters into the plume.

As the plume weakens and spreads over a thicker hypolimnion in March and April, both stratification in the hypolimnion and mixing energy become weaker and are overtaken by effects of the warming epilimnion.

In contrast, St5 in the lower basin (as mentioned

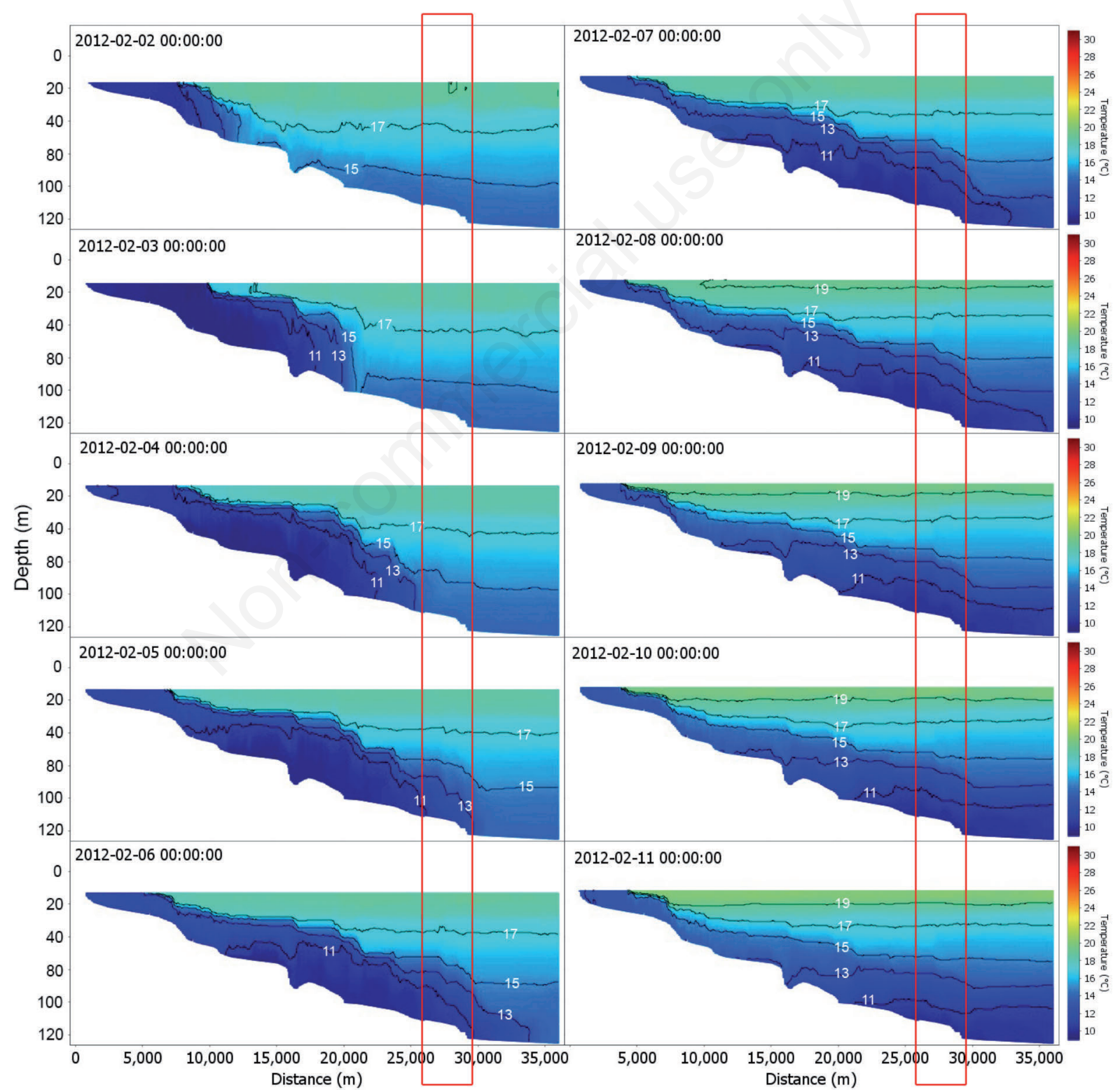

Fig. 5. Pathways of the flood event on February 2 and afterwards, through the reservoir's thalweg. The red boxes denote the canyon separating the two reservoir basins. 


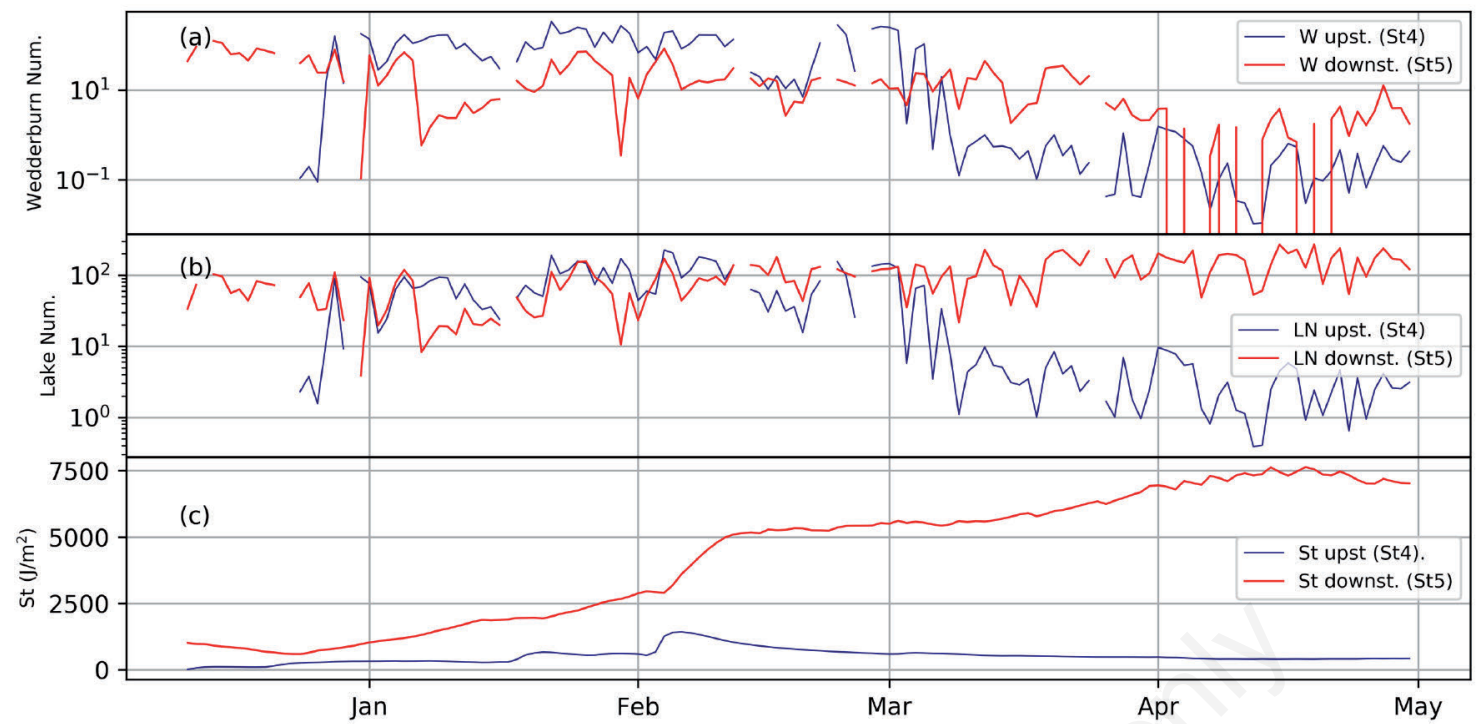

Fig. 6. Wedderburn number (a), Lake Number (b) and Schmidt stability (c), calculated for the AEM3D simulation period (2011-12). Discontinuous time series of $L N$ and $W$ are due to having no wind on the corresponding days.

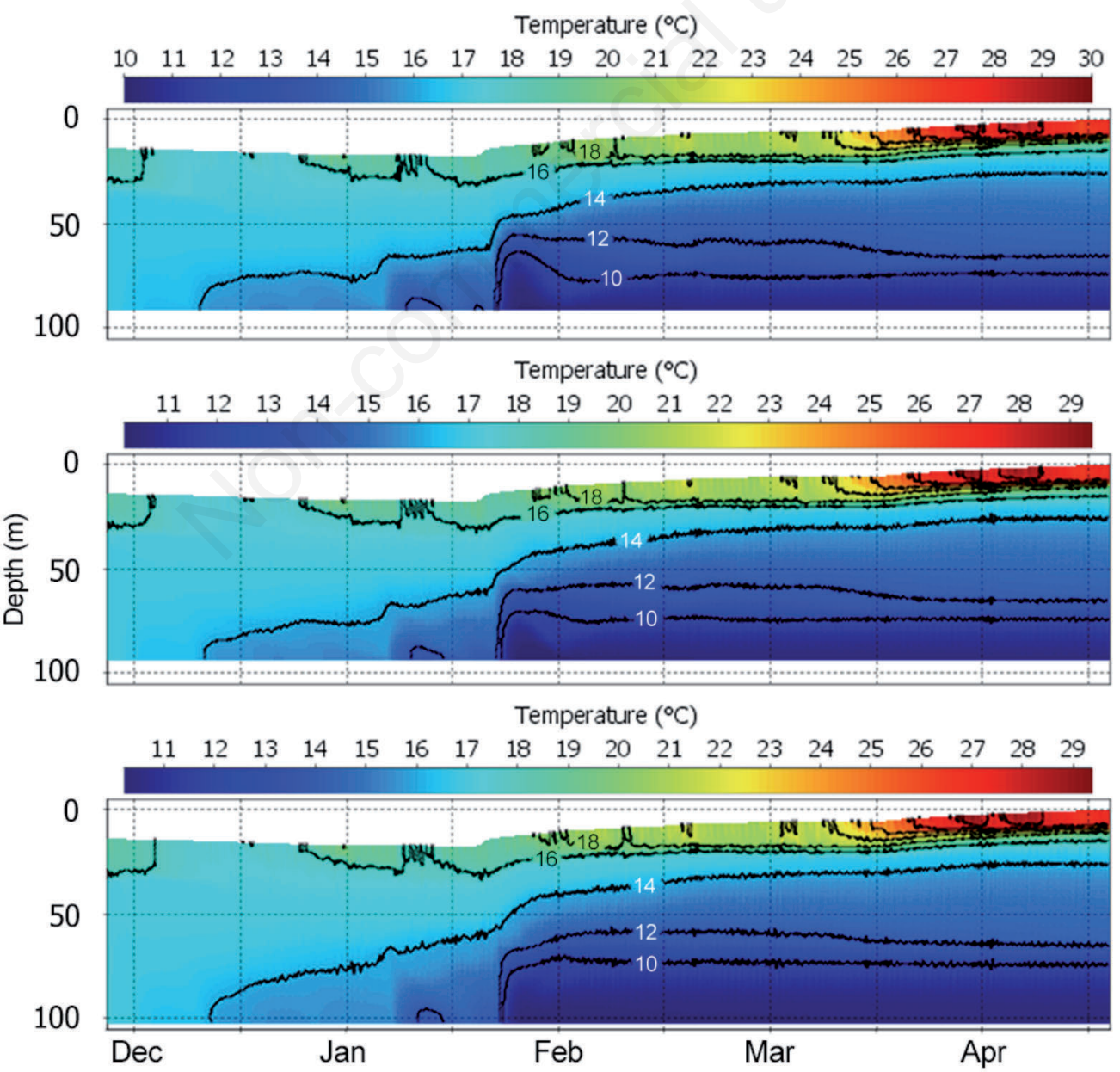

Fig. 7. Simulated water column profiles of the canyon connecting the two basins of the Maroon reservoir: (a) upstream of the canyon, (b) middle of the canyon, and (c) downstream of the canyon. 
above in reference to Fig. 3) never sees a strong effect of the density current. Instead, a relatively consistent large $L_{N}$ throughout the period is obtained, with $W$ being initially large and variable, then dropping rapidly in April with the onset of epilimnion warming by atmospheric forcing. The large $L_{N}$ indicates that the lake in the lower basin remains stratified while the decreasing $W$ is evidence that the lake response to wind forcing is mainly in the epilimnion and does not significantly affect the thermocline or hypolimnion. Once $W$ drops below unity, the baroclinic restoring force reaches a sufficiently strong level to limit the surface mixing to the upper $4 \mathrm{~m}$ of the water column.

The analysis above is consistent with the evolution of $S_{t}$ in the upper and lower basins (Fig. 6c). At the onset of the simulation, both basins begin with relatively low stability as there is not much solar radiation forcing of the lake's surface in the wintertime. As time goes on, the upper basin $S_{t}$ shows a small increase with the propagation of the density plume and then settles down to a smaller value than the $S_{t}$ of the lower basin. The smaller value of $S_{t}$ in the upper basin is consistent with the higher center of gravity $\left(z_{g}\right)$ of the cross-sections in this shallower region of the reservoir. In contrast, the $S_{t}$ of the lower basin is steadily increasing over time, associated initially with the inflow of colder water and then later with the increasing spring temperature in the epilimnion. These findings are consistent with the temperature profiles of St4 (upper basin) and St5 (lower basin) as discussed above for Fig. 3.

\section{Hydrodynamic effects}

The hydrodynamic processes in the narrow canyon connecting the two basins of the Maroon reservoir can be noticed from the anomalies of three simulated temperature profiles in Fig. 7, taken at three locations (shown in Fig. 1c), and are separated by a distance of $1000 \mathrm{~m}$. The most upstream profile (Fig. 7a) shows the strong arrival of the head of the density current, similar to what occurred at station St4 in the upper basin (Fig. 3e), whereas the most downstream profile (Fig. 7c) exhibits the simple filling behavior by cold water in the hypolimnion, similar to what has been observed at station $\mathrm{St} 5$ in the lower basin (see Fig. 3). The central canyon profile (Fig. 7b) represents clearly a transition between the two sections named.

A more quantitative picture of the processes occurring in the narrow canyon is presented in Fig. 8 which shows the time series of the temperature anomalies (temperature relative to the mean) at three discrete levels of the water column in the three canyon sections. These anomalies show clearly the signatures of the underflow at the upper and middle canyon sites at 15 and $30 \mathrm{~m}$ above the bottom, whereas at the downstream site only a very small signature of the density current is seen at $15 \mathrm{~m}$ above the bottom, indicating that by then the current has slowed and spread. This transition from the upper-basin behavior to the simple filling behavior of the density current in the narrow canyon is also seen in Fig. 5 discussed earlier where the contours do not follow the bottom topography through the canyon and a sharp downward bending of the temperature contours occurs in the hypolimnion therein.

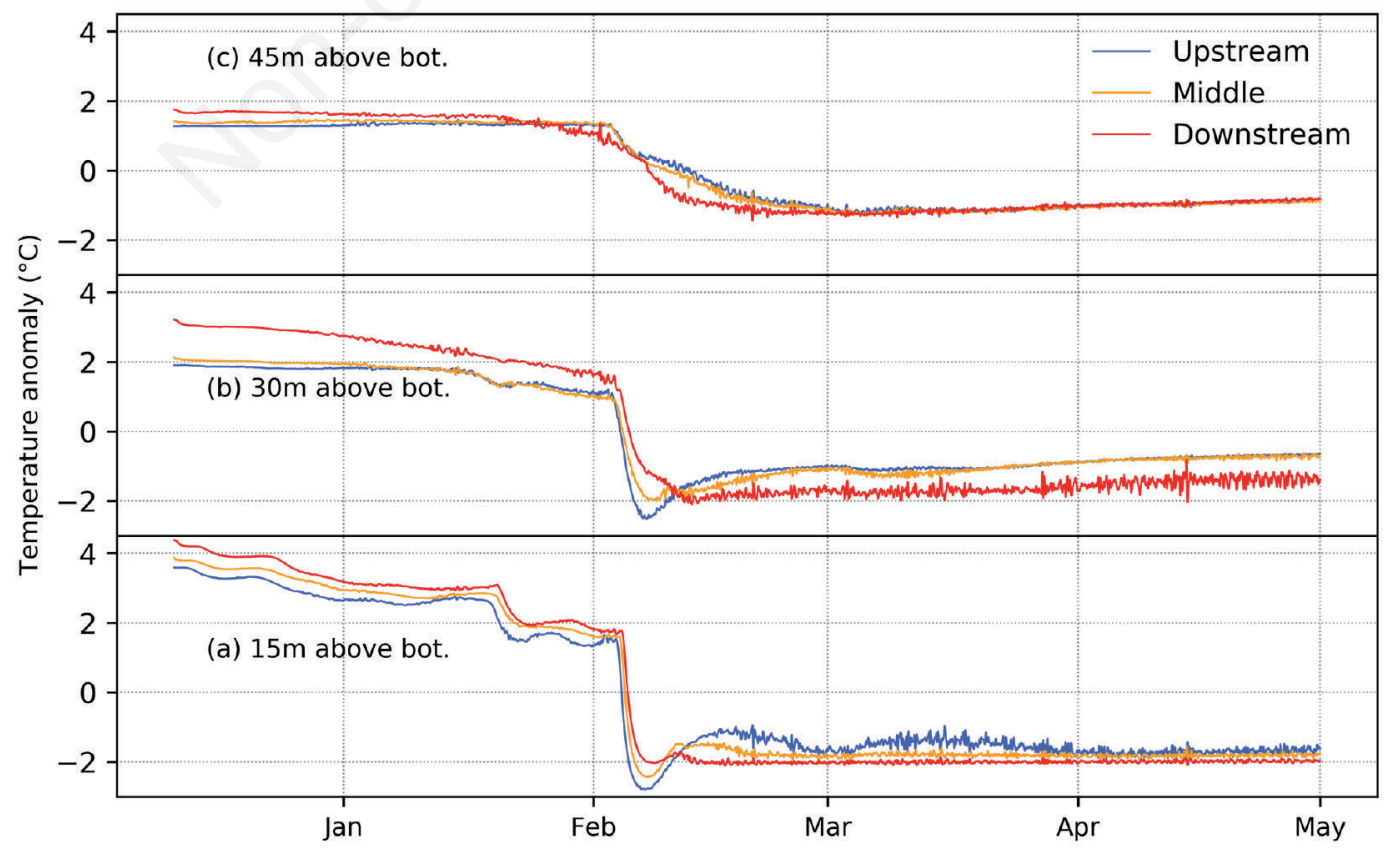

Fig. 8. Anomalies of water temperature at selected elevations of upstream, middle and downstream of the canyon. 


\section{Energy balance}

Potential energy has been previously used to analyze lake dynamics and behavior (Antenucci and Imberger, 2001). As the AEM3D simulation provides density data over the entire lake, it is possible to partition the total potential energy into i) background (BPE), and ii) available (APE). BPE is defined as the potential energy of the system when the water is adiabatically brought to rest whereas APE is defined as the difference between BPE and the total potential energy. In general, increased BPE is a sign of i) irreversible mixing that raises dense water, or ii) an influx of dense water that raises the water level or displaces less-dense water. Therefore, the BPE is a good measure to study energy variations due to density currents.

Fig. $9 \mathrm{~b}$ shows the BPE at the upstream, middle and the downstream sections of the canyon (circled in Fig. 1c). One can notice that after each of the floods on January 14 and February 2, the upstream BPE rises, but returns then again roughly to its initial value. This indicates that the cold and dense water passes through the upstream section and does not return (except as mixed water). This rise is less pronounced in the downstream section in Fig. 9b, so that the fall of the BPE is also not as severe as that of the upstream section.

After the two flood events, each of the canyon sections shows different Schmidt stability values $S_{t}$, as illustrated in Fig. 9c. This effect is strongest after the large February 2 flood when the stability graphs of the three sections diverge dramatically. The $S_{t}$ for the upstream section decreases steadily to its pre-flood value whereas the of the downstream section continues to increase and that of the middle section is relatively invariant. This illustrates that the spring stratification increases the stability of the downstream canyon section (and lower basin) after middle of March but not that of the middle and upstream sections. The implication is that the upper basin, down to the middle of the canyon, is more strongly affected by the mixing processes which compensate the increasing stratification caused by the spring seasonal heating in the epilimnion, with the latter taking over in the lower canyon section.

\section{GENERAL DISCUSSION OF MODEL ERRORS}

The AEM3D model results for the near-bottom water temperatures shown in Fig. 2 give a perspective of the model's validation accuracy over the flooding season. There are three likely contributors to the observed differences between modeled and measured temperature values.

Firstly, the transport of cold water by a density current in the hypolimnion has an inherent accumulative error effect, as the current speed depends on its size and mixing. The hydrodynamic system has a nonlinear feedback between its past and future evolution, so an accumulation of error in the density field leads to a bias error in the speed of propagation of the density front.

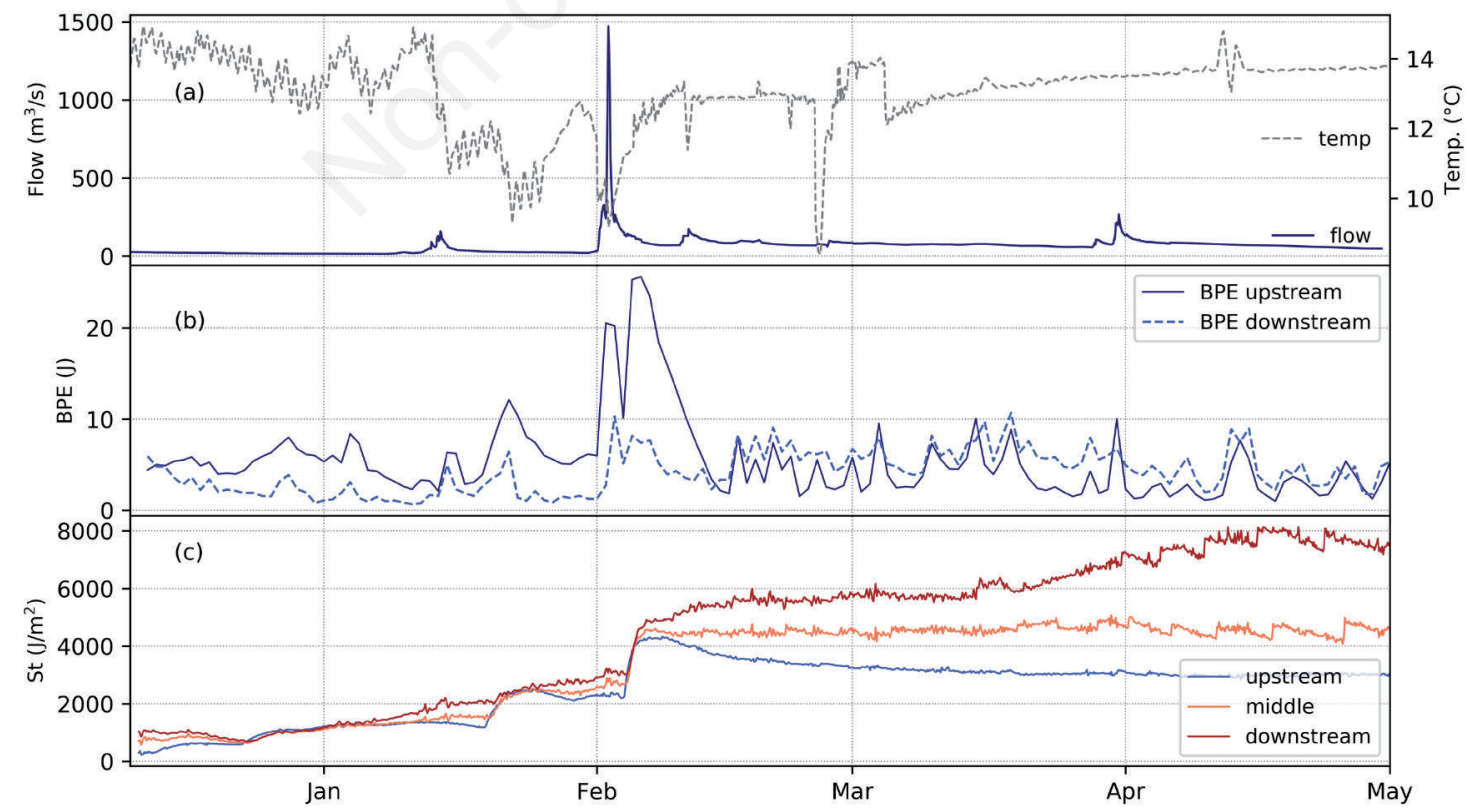

Fig. 9. Maroon River flow rate and temperature (a), background potential energy (BPE) at upstream and downstream sections of the canyon (b) and Schmidt stability value (c) for up-, middle, and downstream sections of the canyon. 
Secondly, the $100 \times 100 \times 1 \mathrm{~m}$ numerical model grid is relatively coarse for properly representing the reservoir's thalweg, as the steep valley morphometry is actually narrower near the bottom than the grid size over much of the domain, especially in the zones upstream of station St4 and in the canyon connecting the upper and lower basins. This coarse-grid effect occurs predominantly in the lower two or three grid cells (which includes the model-data comparison points) and results in a broader cross-sectional area for the model hypolimnion. The misrepresentation of the cross-sectional area in the thalweg will affect the overall thickness of a propagating density plume as well as its speed and mixing.

A third likely source of error is the mechanism proposed by Hodges et al. (2006) who showed that models using the hydrostatic approximation (as AEM3D herein) lead, in the presence of large nonlinear internal waves, to a bias that alters the modeled wave propagation. This typically results in excessive steepening of the front of a model internal wave, as appears to be the case in Fig. 2.

Although refining the model grid would undoubtedly help to resolve the under-resolution problem (2) for the thalweg, a key point of Hodges et al. (2006) is that grid refinement cannot remove the underlying bias associated with the neglect of the non-hydrostatic terms. Instead, refining the grid merely changes the balance between numerical dissipation and numerical dispersion (oscillation) at the wave front, typically leading to waves with greater artificial steepening. In the limit, grid refinement of a hydrostatic model is merely a better solution of the wrong equations and is not necessarily a better representation of the real world. This observation, while somewhat bleak, is actually quite helpful. Instead of wasting more computational time on finer grids, we can simply ask whether our hydrostatic model, while being "wrong" in the sense of Box (1976), is also "useful". For the present purposes, Fig. 2 shows reasonable agreement between modeled and observed water temperatures across all of stations over the five-month simulation horizon. The key density current events occur with similar scales and timing (e.g., rapid cooling in February) and the statistical analyses (Tab. 2) provide further validation. Therefore, the AEM3D hydrodynamic model achieves overall good agreement with the observations, using parameters based solely on literature values. Consequently, this work provides further evidence that 3D state-of-the-art modeling is able to provide valuable insights into various physical reservoir processes, namely, the hydrodynamics of the density currents, and this is accomplished without requiring extensive calibration data.

\section{CONCLUSIONS}

This study presents the application of an uncalibrated 3D hydrodynamic model to the Iranian Maroon reservoir.
Our study shows the important role which the morphology of the reservoir plays in controlling the hydrodynamics in a way that alters the limnological character of the two reservoir basins connected by a narrow canyon. The cold density currents during the winter/spring floods are shown to propagate rapidly through the upper basin but are moderated by the narrow canyon separating the upper and lower basins.

The analysis evaluated the response of the two basins to wind forcing in terms of the Lake Number $\left(L_{N}\right)$, Wedderburn number $(W)$ and the Schmidt stability term $\left(S_{t}\right)$. The results indicate that the upper basin is less stable than the downstream one (despite stronger stratification of the underflow) and is more prone to mixing by both wind and a flowing gravity current (cold plume in the wake of the two flood events). The lower basin is more stable and the main response to wind forcing is limited to mixing in the epilimnion.

The analysis of the canyon hydrodynamics shows further that the narrow constriction is effectively partitioning the reservoir into two basins with different stratification and mixing behaviors. At the downstream section of the canyon, the background potential energy (BPE), after the passing of each density current (after the recession limb of the two flood events) shows higher values than those before the flood, whereas the opposite is observed for the upstream section of the canyon. These differences are even more prominently visible from the Schmidt stability values $\left(S_{t}\right)$ of the up- and downstream sections of the canyon. Due to stronger mixing processes, $S_{t}$ for the upstream canyon section initially decreases and undergoes a rapid increase due to the flood events' bore flow, but then steadily regains its pre-flood value. In contrast, the $S_{t}$ for downstream canyon section (and that of the lower basin) continues to increase due to increased stratification by the spring seasonal heating in the epilimnion.

From this analysis we are able show the canyon morphology in the Maroon reservoir dissipates the sharp front of the flood bore as it propagates downstream into the lower basin during the two flood events. These effects are reflected in the stratification and mixing behaviors that, in turn, may affect the evolution of reservoir's water quality over seasonal timescales.

The reservoir morphology clearly affects the overall energy balance and the fate of density currents, which are important factors in the sedimentation within the reservoir. It follows that future studies should examine suspended solids and turbidity, whose distribution may be affected by the propagation and dissipation of the flood underflows. However, to do so properly, long-term observations with thermistor chains that cover the full depth of the lake are needed. Furthermore, additional sensors upstream and downstream at the entrance and exit 
to the canyon would be particularly valuable for future modeling.

\section{ACKNOWLEDGMENTS}

Computational resources of this modeling study were provided by the computation center of the University of Kassel. We express our sincere thanks to Prof. Jörg Imberger and Dr. Chris Dallimore for their constructive advices regarding this study and the AEM3D model. We also thank Prof. Mehdi Ghomeshi for his invaluable advices and information regarding the Maroon River and reservoir. We appreciate the Iranian Meteorological Organization for supporting us with the meteorological data and Mr. Ali Mohammadi-Ahari for providing us with the river flow data to carry out this study.

\section{REFERENCES}

Alizadeh A, Khalili N, 2009. [Estimation of Angstrom coefficient and developing a regression equation for solar radiation estimation (case study: Mashhad)].[Article in Persian]. J. Water Soil 23:229-238

Allen RG, Pereira LS, Raes D, Smith M, 1998. Crop Evapotranspiration - Guidelines for Computing Crop Water Requirements. FAO Irrigation and drainage paper 56. Food and Agriculture Organization of the United Nations, Rome.

An S, Julien PY, 2014. Three-dimensional modeling of turbid density currents in Imha Reservoir, South Korea. J. Hydraul. Eng. 140:05014004.

Amadori M, Piccolroaz S, Dijkstra HA, Toffolon M (2019). What makes an elongated lake 'large'? Scales from winddriven steady circulation on a rotating Earth. J. Great Lakes Res. (in press). doi: 10.1016/j.jglr.2019.10.013.

Ångström A, 1924. Solar and terrestrial radiation. Q. J. R. Meteorol. Soc. 50:121-125.

Antenucci JP, Imberger J, 2001. Energetics of long internal gravity waves in large lakes. Limnol. Oceanogr. 46:1760-1773.

Arakawa A, Lamb VR, 1977. Computational design of the basic dynamical processes of the UCLA general circulation model, p. 173-265. In: Chang J. (ed.), General Circulation Models of the Atmosphere. Methods in Computational Physics. Elsevier.

Botelho Daniel A, Imberger J, 2007. Dissolved oxygen response to wind-inflow interactions in a stratified reservoir. Limnol. Oceanogr. 52:2027-2052.

Box GEP, 1976. Science and statistics. J. Am. Stat. Ass. 71:791-799.

Bourent PE, Dartus D, Tassin B, Vincon-Leite B, 1999. Numerical investigation of plunging density current. J. Hydraul. Eng. 125:584-594

Cassulli V, Cheng RT, 1992. Semi-implicit finite difference methods for three-dimensional shallow water flow. Int. J. Numer. Meth. 15:629-648.

Chung SW, Hipsey MR, Imberger J, 2009. Modelling the propagation of turbid density inflows into a stratified lake:
Daecheong Reservoir, Korea. Environ. Model. Softw. 24:1467-1482.

Cortés A, Fleenor WE, Wells MG, de Vicente I, Rueda FJ, 2014. Pathways of river water to the surface layers of stratified reservoirs. Limnol. Oceanogr. 59:233-250.

Ford DE, Johnson LS, 1986. An assessment of reservoir mixing processes, technical report for US Army Corps of Engineers. Ford Thornton Norton and associates Ltd., USA.

Hajjam S, Jamei M, 2009. [Estimation of solar radiation parameter (sunshine hours) and Angstrom coefficients in Khuzestan Province].[Article in Persian]. Proceedings 10th National Conf. of Irrigation and Evaporation Reduction, Kerman, Iran.

Hamilton, DP, Schladow, SG, 1997. Prediction of water quality in lakes and reservoirs: Part I-Model description. Ecol. Model. 96:91-110.

Hayes NM, Deemer BR, Corman JR, Razavi R, Strok KE, 2017. Key differences between lakes and reservoirs modify climate signals: A case for a new conceptual model. Limnol. Oceanogr. Lett. 2:47-62.

Hipsey MR, Antenucci JP, Brookes JD, 2008. A generic, process-based model of microbial pollution in aquatic systems. Water Resour. Res. 44:W07408. doi: 10.1029/2007WR006395.

Hodges BR, Dallimore C, 2016. Aquatic Ecosystem Model: AEM3D, User manual. Hydronumerics, Australia.

Hodges BR, Imberger J, Saggio A, Winters KB, 2000. Modeling basin-scale internal waves in a stratified lake. Limnol. Oceanogr. 45:1603-1620.

Hodges BR, Laval B, Wadzuk BM, 2006. Numerical error assessment and a temporal horizon for internal waves in a hydrostatic model. Ocean Model. 13:44-64.

Hogg CAR, Dalziel SB, Huppert HE, Imberger J, 2017. Inclined gravity currents filling basins: the impact of peeling detrainment on transport and vertical structure. J. Fluid Mech. 820:400-423.

Hutchinson GE, Loffler H, 1956. The thermal classification of lakes. P. Natl. Acad. Sci. 42:84-86.

Hutchinson GE, 1957. A treatise on limnology. J. Wiley \& Sons, Inc., New York.

Hürzeler BE, Imberger J, Ivey GN, 1996. Dynamics of turbidity current with reversing buoyancy. J. Hydr. Engin. 122:230-236

Imberger J, Patterson JC, 1990. Physical limnology. Adv. Appl. Mech. 27:303-475.

Ji Z-G, 2008. Hydrodynamics and water quality: modeling rivers, lakes, and estuaries. J. Wiley \& Sons, Inc., New York.

Jørgensen SE, Löffler H, Rast W, Straškraba M, 2005. Lake and reservoir management. Elsevier Inc.

Kennedy RH, Thornton KW, Ford DE, 1985. Characterization of the reservoir ecosystem. In: D. Gunnison (ed.), Microbial Processes in Reservoirs. Springer.

Kim, Y. and B. Kim. 2006. Application of a 2-dimensional water quality model (CE-QUAL-W2) to the turbidity interflow in a deep reservoir (Lake Soyang, Korea). Lake Reserv. Manage. 22:213-222. https://doi.org/10.1080/07438140609353898.

Lindim Fontes C, 2010. Modelling of water quality in the Alqueva Reservoir, Portugal. PhD thesis, University of Minho, Portugal.

Löffler H, 2004. The origin of lake basins, p. 8-60. In: P.E. 
O'Sullivan and C.S. Reynolds (eds.), The lakes handbook. Blackwell Publishing.

Marti CL, Imberger J, Garibaldi L, Leoni B, 2016. Using time scales to characterize phytoplankton assemblages in a deep subalpine lake during the thermal stratification period: Lake Iseo, Italy. Water Resour. Res. 52:1762-1780.

Mehrabani R, Makvandi A, Nekouyanfar M, Hassounizadeh H, 2013. Tracing and measurement of turbidity current in maroon dam. Proceedings 9th Int. River Engineering Conf., Ahwaz, Iran.

Panse S, 2013. Background and available potential energy in numerical simulations of a Boussinesq Fluid. Master's Thesis 1911 - February 2014. 1002.

Read JS, Hamilton DP, Jones ID, Muraoka K, Winslow LA, Kroiss R, Wu CH, Gaiser E, 2011. Derivation of lake mixing and stratification indices from high-resolution lake buoy data. Environ. Model. Softw. 26:1325-1336.

Robertson DM and Imberger J, 1994. Lake Number, a quantitative indicator of mixing used to estimate changes in dissolved oxygen. Int. Revue Ges. Hydrobiol. 79: 159-176.

Rueda FJ, McIntyre S, 2010. Modelling the fate and transport of negatively buoyant storm-river water in small multi-basin lakes. Environ. Model. Softw. 25:146-157.

Scheu KR, Fong D, Monismith SG, Fringer OB, 2018. Modeling sedimentation dynamics of sediment-laden river intrusions in a rotationally-influenced, stratified lake. Water Resour. Res. 54:4084- 4107.

Schladow SG, Hamilton DP, 1997. Prediction of water quality in lakes and reservoirs: Part II-Model calibration, sensitivity analysis and application. Ecol. Model. 96:111-123.

Schmidt W, 1928. [Ueber Temperatur and Stabilitaetsverhaltnisse von Seen].[Article in German]. Geographiska Annaler 10:145-177.

Thornton JA, Rast W, Steele A, 1996. Reservoirs. In: D. Chapman (Ed.), Water Quality Assessments, 2nd Ed. Chapman and Hall, London, 369-412.

USACE U.S. Army Corps of Engineers, 1987. Reservoir water quality analysis, Engineer Manual. USA.

Valerio G, Pilotti M, Marti CL, Imberger J, 2012. The structure of basin-scale internal waves in a stratified lake in response to lake bathymetry and wind spatial and temporal distribution: Lake Iseo, Italy. Limnol. Oceanogr. 57:772-786.

Vincent WF, Gibbs MM, Spigel RH, 1991. Eutrophication processes regulated by a plunging river inflow. Hydrobiologia 226: 51-63.

Winters K, Lombard P, Riley J, D’Asaro E, 1995. Available potential energy and mixing in density-stratified fluids. J. Fluid Mech. 289:115-128. doi:10.1017/S002211209500125X.

Wüest A, Lorke A, 2003. Small-scale hydrodynamics in lakes. Annu. Rev. Fluid Mech. 35:373-412. doi: 10.1146/annurev. fluid.35.101101.161220.

Yang K, Koike T, 2005. A general model to estimate hourly and daily solar radiation for hydrological studies. Water Resour. Res. 41:W10403. doi: 10.1029/2005WR003976

Zamani B, Koch M, Hodges BR, Fakheri-Fard A, 2018. Preimpoundment assessment of the limnological processes and eutrophication in a reservoir using three-dimensional modeling: Abolabbas reservoir, Iran. J. Appl. Water Engin. Res. 6:48-61. doi: 10.1080/23249676.2016.1209440.

Zamani B, Koch M, 2020. Comparison between two hydrodynamic models in simulating physical processes of a reservoir with complex morphology: Maroon Reservoir. Water 12:814. 